\title{
Where is creativity in the city? Integrating qualitative and GIS methods
}

\section{Chris Brennan-Horley, Chris Gibson $\uparrow$}

School of Earth and Environmental Sciences, University of Wollongong, Wollongong, NSW 2522, Australia; e-mail: chrisbh@uow.edu.au,cgibson@uow.edu.au

Received 19 August 2008; in revised form 23 December 2008; published online 14 September 2009

\begin{abstract}
This paper discusses a new blend of methods developed to answer the question of where creativity is in the city. Experimentation with new methods was required because of empirical shortcomings with existing creative city research techniques; but also to respond to increasingly important questions of where nascent economic activities occur outside the formal sector, and governmental spheres of planning and economic development policy. In response we discuss here how qualitative methods can be used to address such concerns, based on experiences from an empirical project charged with the task of documenting creative activity in Darwin - a small city in Australia's tropical north. Diverse creative practitioners were interviewed about their interactions with the city-and hard-copy maps were used as anchoring devices around spatially orientated interview questions. Results from this interview-mapping process were accumulated and analysed in a geographical information system (GIS). Digital maps produced by this method revealed patterns of concentration and imagined 'epicentres' of creativity in Darwin, and showed how types of sites and spaces of the city are imagined as 'creative' in different ways. Qualitative mapping of creativity enabled the teasing out of contradictory and divergent stories of the location of creativity in the urban landscape. The opportunities which such methods present for researchers interested in how economic activities are 'lived' by workers, situated in social networks, and reproduced in everyday, material, spaces of the city are described.
\end{abstract}

\section{Introduction}

Geographical concepts and metaphors such as 'clusters', 'networks', 'flows', 'creative precincts', and 'cultural districts' have increasingly infused creative industries research and policy making (Gibson and Kong, 2005). This partly stems from the important role that geographers have played in documenting the rise and complexity of cultural and creative industries (Power and Scott, 2004; Pratt, 1997; Scott, 2000), but also, continued empirical research on economic dimensions of creative industries necessitates analysis of the location of firms, agglomeration tendencies, proximate learning, tacit knowledge spillovers, and the importance of precinct-specific 'buzz' effects for creative entrepreneurs (Bathelt and Gräf, 2008; Dahlström and Hermelin, 2007; Grabher, 2002; Maskell and Malmberg, 1999; Reimer et al, 2008; Vang, 2007). Implicitly, if not explicitly, this body of research is therefore concerned with the question 'where is creativity in the city?'

In a most basic sense this is an important question because culture and creativity have grown as components of national and urban economies [notwithstanding debates about their conceptualisation, and 'true' measured value (see Throsby, 2001)]; and because forms of innovation at the heart of creative industries are likely to manifest themselves in rather more different spaces and sites from those in earlier phases of capitalism (Bathelt et al, 2005; Fasche, 2006). Where creativity is in the city also matters as a research and policy question because when attempts are made to reorientate urban economies around creativity, answers to this question increasingly influence policy formation and the dedication of fiscal resources [with sometimes deleterious effects (see Oakley, 2004; 2006; Wilson and Keil, 2008)]. Researchers both sympathetic to and 
sceptical of creative city planning and policy making (eg Christophers, 2008; Gibson and Klocker, 2005; Peck, 2005; Ward, 2003), have much to gain from spatially literate responses to the questions of where creativity is generated in the city. By documenting creativity in the city geographically, researchers are better able to critique the distribution of governmental resources; and more deeply challenge problematic assumptions about 'more or less creative' places, industries, and people.

Existing methodological techniques used to answer the question of where creativity is in the city include spatial analysis of intrafirm and industry structures and competitive dynamics; quantifications of creative workers in local labour markets (eg through analysing census data on employment across proximate spatial units); and mapping firm locations and densities across cities and regions (with accompanying analysis of 'cluster effects') (see DCMS, 2008; Gibson and Brennan-Horley, 2006; Gibson et al, 2002; Markusen et al, 2008; Pratt, 1997; Scott, 2000; Throsby, 2001; Watson, 2008). Underpinning these techniques have been debates about what 'creativity' is, in an economic sense, and what the 'creative industries' might constitute, as opposed to the 'cultural' or 'arts' industries (Costa et al, 2007; Gibson and Kong, 2005). In some research, where the term 'cultural industries' is preferred, arts and performance occupations such as musicians, writers, actors, and painters are conceptualised as at the 'core' of concentric rings of 'more-creative' or 'less-creative' employment (see Throsby, 2008). This is justified because of the creative authorial process in the performing and visual arts. In the UK and USA, the wider term 'creative industries' has risen to prominence instead after the success of key authors and books such as Richard Florida's The Rise of the Creative Class (2002). Economic work on 'creative industries' is about defining and theorising the internal capitalist logics of a range of sectors where creativity and intellectual property generation are at the core of profit-growth agendas. Subsequent policy ideas have circulated internationally about how creativity and culture are vital to economic performance, and can catalyse in-migration of lucrative expertise and investment (Kong et al, 2006). It is not our purpose in this paper to resolve the debate about what constitutes a 'creative' industry, and whether this is a superior term to that of 'cultural industry'. Instead, our aim is to reframe research possibilities by talking to workers in creative industries (however defined) about how their creativity is situated in the material spaces of the city. The point to make here is that in previous literatures, irrespective of whether the emphasis is on the arts, or cultural or creative industries, energies have been directed towards quantifying geographical patterns of concentration, dispersal, networks, and relationships across and between firms who specialise in the outputs of creative activities-adopting a broadly political economic epistemology familiar within economic geography since the 1980s (Scott, 2006a). The emphasis has been less on the creative process itself, in a sociological sense, and more on mapping labour and firm activity and density in Cartesian urban space.

In this paper we discuss an alternative methodology developed to answer the same question about the location of creativity in the city, but based specifically on the qualitative perspectives of creative workers - defined broadly-when prompted to discuss their actual working lives (and creative processes). Our approach relates to previous theories on cultural and creative industries (inasmuch as it focuses on creative activities). But, through methodological experimentation, we take a different route towards mapping a geography of creativity, as experienced by practitioners themselves, in their city. Taking a different methodological route was necessary in the context of our research because of the unique case-study city at hand (discussed further below); but also in response to criticisms which have been made about the tendency in creative industry research to focus on the mapping of the firm and labour markets 
at a macroscale, rather than the experiences of workers themselves (Gibson, 2003; Reimer, 2009). In quantitative analysis of creative industry employment or firm locational distribution, the microscale stories remain untold of exactly how creativity is realised, and by whom, in the material spaces of the city (Drake, 2003). This is particularly pertinent for work in the vast parts of the creative economy that constitute economically 'marginal' creative activities - positioned at the edges of the formal/informal economy.

Indeed, while within creative industries there are clearly identifiable careers and exploitable intellectual property products (eg film production, architecture, design), there are prevalent forms of work that move between mere pastime and formality; between incidental experimentation and commercial exploitation (Gibson, 2003). In cultural economics this is theorised as a reserve army of highly precarious labour (see Gill and Pratt, 2008; Reimer, 2009; Ross, 2008), often at the whim of large entertainment corporations who sign creative producers to short-term contracts, and who strategically overproduce music, book, and magazine releases in the expectation that only some will be 'hits' which return runaway profits. Creativity is also the sphere of freelancers, radical artists, the temporarily employed, and barely viable microbusinesses (Banks, 2006). Various concepts such as the independent sector, 'pro-am' labour (amateurs operating at a professional quality, but not getting paid for it), soft infrastructure, contingent networks, and network sociality have attempted to capture this loose, frequently (self-)exploitative set of activities (Flew et al, 2001; Hearn et al, 2004; Neff, 2005; Neff et al, 2005; Shorthose, 2004; Wittel, 2001). Such activities are often based on informal and unstructured creative relationships. These relationships can be as much cultural as they are economic, as friends or acquaintances come together to produce, express, or perform in a myriad of configurations, sometimes intersecting with microbusinesses and other more formal sectors of the economy. Indeed, in many places (including Darwin, where our study was located) nascent economic formations find their genesis in social and cultural formations-subcultures, fan groups, Facebook communities, networks of friends (Brennan-Horley, 2007; Cohen, 2007; Gibson, 2000). Whereas more stable, and hence more visible, occupations have organised systems of schooling, professional associations, and career development, leading to greater visibility in official statistics (and in empirical research on creative cities), within the informal, independent, subcultural, or 'pro - am' communities working lives are fluid and virtually impossible to quantify (Gibson et al, 2002; McRobbie, 2002).

Shorthose has accordingly called for a "more sectorally specific ethnography of creativity" which can "focus upon the hidden, informal economic and cultural processes, rather than concentrating upon economic indicators and outcomes which by definition exclude these" (2004, page 159). In a similar vein but with a more geographic angle, Pratt (2004, page 63) has similarly argued that creativity:

"is more than the simple presence or absence of resources in a creative ecosystem; it is as much about how they are made available and under what terms, and where they are located, physically and structurally, in appropriate linkages, networks and institutions."

If the location of creative work remains opaque, it is possible instead to look for anchoring points in the urban landscape where particular configurations may manifest, however briefly, and invite people to describe their creativity in relation to them. This approach provides a way of uncovering grassroots, and even hidden, aspects of the creative life of cities. Locations that can be revealed through a spatial ethnography include sites of intersection between the formal and informal sectors; between sociocultural activities and the sphere of paid employment; between 'core' and 'other' forms of creativity. This kind of knowledge about the spatiality of cultural activities can guard against certain kinds of exclusions in creative-industry research 
and policy making (by including those sometimes written out of analysis because of their 'marginal' or 'uncommercial' status); and can ultimately help prevent poor positioning of cultural facilities and creative precinct schemes (Evans and Foord, 2008). In this fashion, understanding more about the 'where' of creativity has tangible spatial planning and cultural outcomes.

Viewing creativity in this way requires 'grassroots up' approaches to geographical analysis: creative workers are active agents who literally produce the creative city through their everyday practices, working lives, movements, and relationships with and imaginations of their city. We therefore looked to social and cultural geography for methodological directions - specifically, interviews and ethnographic research - but sought to combine these with digital mapping technologies that are able to visualise geographical patterns and divergences. Such an approach extends other interviewbased research about the interplay between place and creative activity (Drake, 2003), tourist perceptions of creative spaces (Pappalepore, 2008), and creative countermapping efforts (Rossiter et al, 2008). Like these studies, our point is that by experimenting with new blends of methods, nuanced and geographically rich pictures of the location of creativity in the city are possible, and differences can be revealed between how spaces and sites in the city are used, imagined, and described as 'creative'.

\section{Darwin - a remote, tropical, creative city?}

Our analysis is situated in Darwin, Australia - a city that has an unusual internal spatial layout, and which has a mix of demographic, remoteness, and postcolonial cultural features that make it atypical in creative city research. The analysis forms part of a wider project-Creative Tropical City: Mapping Darwin's Creative Industries-a three-year exercise funded by the Federal Government's Australian Research Council, Darwin City Council, the Northern Territory Department of the Chief Minister, and the Department of Natural Resources, Environment and the Arts. The project has been designed to understand Darwin's existing creative industries (whatever they might be) and to provide policy makers with information to inform future policy decisions.

Darwin is small (with a population of 75000 in 2006), and physically remote within Australia in a way which most outsiders probably struggle to fully comprehend. It is $1500 \mathrm{~km}$ by road to the nearest substantial town (Alice Springs, which has a population of only 25 000) and $3000 \mathrm{~km}$ to the nearest Australian metropolis (Adelaide). London is closer to Cairo in Egypt than Darwin is to Sydney, Melbourne, or Perth. Darwin holds a particular place in the Australian cultural imaginary, as a strategic military 'outpost' on the northern frontier (as depicted in the recent feature film Australia), a tourism 'gateway' to Southeast Asia and Kakadu National Park (a nearby 'wilderness' World Heritage site with iconic Aboriginal rock art and cultural heritage), and as a focal point for (post)colonial struggles over mineral resources and land.

Contradicting Darwin's real and imagined remoteness are its proximity to Asia, and its connections to other places through flows of seasonal workers, temporary residents, and tourists (in particular international backpackers). Darwin is only $700 \mathrm{~km}$ from East Timor, and is closer both to Jakarta and to Singapore than to Sydney. Reflecting this, Darwin has a highly multicultural population with many well-established Southeast Asian communities. There is a much larger official Indigenous population $(12.5 \%)$ compared with either the national average $(2.5 \%)$ or any other Australian capital city, and Darwin is a focal point for movements of Aboriginal people between several hundred scattered tiny settlements across the thousands of square kilometres of the surrounding 'Top End' region. The city receives over 1.5 million short-term tourist visitors per annum, mostly from overseas. The tourism industry is dominated by relatively low-paid seasonal employment (hotel and restaurant jobs often 
filled by backpackers or southern Australians seeking work in the warm northern winter). Although mining is also important, most mining workers and executives fly in to Darwin and the surrounding mines to work on fortnightly shifts, and then fly back to Perth, Brisbane, or Adelaide. Military personnel and their families make up about $20 \%$ of Darwin's population, further contributing to a wider 'population churn' where approximately one quarter of the resident population move somewhere else every five years [compared with less than $10 \%$ for most other states (see Luckman et al, 2009)].

Darwin's unique spatial layout is a function of its environment, remoteness, and location on a peninsula (figure 1), and further complicated by its destructive history. Surveyed for urban development in the late 1890s, in the 20th century the city was demolished four times; by cyclone (twice), fire, and bombing during World War II. The result is a low-density, cyclone-proofed city of post-1970s planning schemes, in an intense climate, proximate to beaches, swamps, bays, and substantial Aboriginal land holdings. Darwin has high rates of car dependency, decentralised shopping centres, and reliance on air conditioning (the extreme heat and humidity in the wet season further contribute to a lack of pedestrianisation). The dominant architectures - stormproof public buildings of reinforced concrete, and detached housing on stilts with extensive louvres - have only recently been supplemented with high-rise apartmentblock developments in the city's central business district as new technologies and building methods adapt to required tropical building codes. Unlike northern hemisphere (often deindustrialising) cities typically subject to creative city analysis, Darwin has no ex-industrial inner city of warehouses and terrace housing capable of gentrified reinvention as 'creative precincts'. Other than one main street in the original city centre, which is the focal point for backpacker clubs and hostels, there are no European-style concentrations of cafes and boutiques. With its only university located at the edge of the city, near beaches, Aboriginal 'town camps' (semiformal shanty settlements for often highly itinerant people), tropical marshlands, and a suburban undercover shopping mall, Darwin could not be more different from Manchester or Barcelona.

Yet Darwin clearly has visible signs of creativity: there are television and radio stations, advertising agencies, design firms, 'alternative' music scenes, poetry readings, several dry-season cultural festivals, and vibrant night markets filled with stalls selling locally made arts and crafts. Backpacker tourism has supported new markets for Aboriginal visual art, didjeridu manufacturing, and live music (Luckman et al, 2008); and within different ethnic communities musical and performance traditions have persisted across generations, producing a unique cultural heritage (Hayward, 2005).

Instead of solely relying on mapping techniques based on 'official' statistics, we instead sought qualitative geographical data sourced from in-depth interviews with people in very diverse vernacular 'creative' pursuits - from established industries like architecture and design, to music and visual art, jewellery design, tattooing, and leather whip making. Being small and remote, there are few large established creative industry firms in the mould of those observed in northern hemisphere studies: most people working in creativity do so as individuals, often without remuneration, or combining part-time or intermittent creative work with other 'day jobs'. Many are within 'scenes' that are hobbyist or obscure in nature, and work wholly within the city's informal sector (and are thus not captured by official employment or business location statistics). Statistical analysis and quantitative mapping of creative employment in Darwin early in our research process confirmed these serious empirical shortcomings and limitations (Gibson and Brennan-Horley, 2007). Some element of 'countermapping' was thus required (cf Rossiter et al, 2008).

Reflecting our desire to document vernacular perspectives, 98 semistructured interviews were conducted in Darwin with people from 29 different ethnic backgrounds 
(including 10 people from several different tribal Aboriginal backgrounds), involved in 46 different creative activities (table 1). Over 600000 words of transcribed interviews resulted. Participants were recruited by identifying individuals from existing commercial sources, snowballing through social networks, and deliberately targeting a diversity
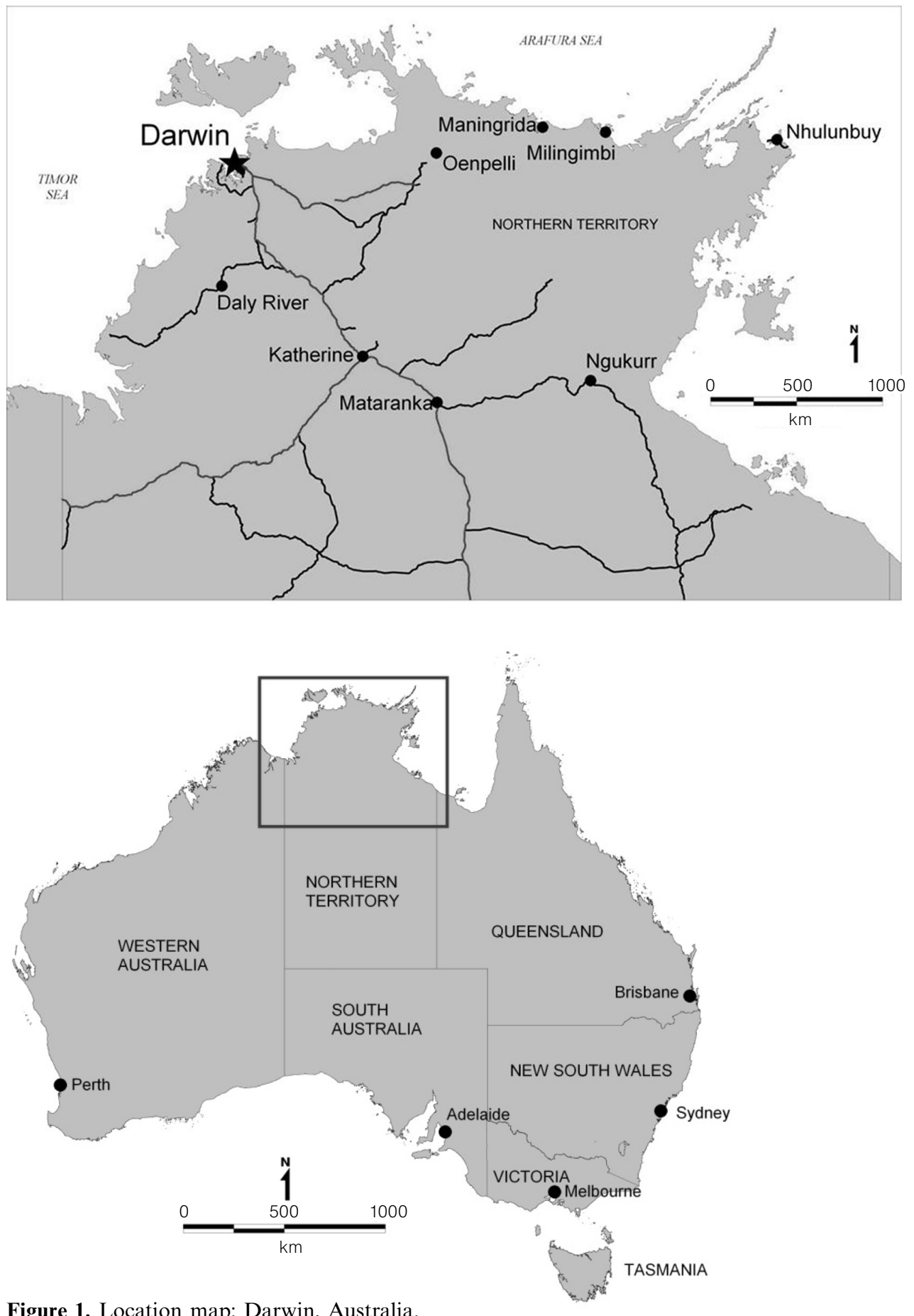

Figure 1. Location map: Darwin, Australia. 
Table 1. Types of creative workers interviewed, 2007-08, with numbers of interviews shown in parentheses.

\begin{tabular}{lll} 
Actor (5) & Dancer (2) & Multimedia designer (3) \\
Actor/director (1) & Designer (1) & Musician (7) \\
Advertiser (1) & Director (1) & Performing artist (4) \\
Architect (7) & Educator (4) & Photographer (6) \\
Artist (5) & Entertainment reporter (1) & Playwright (1) \\
Artistic director (5) & Festival and event manager (5) & Printmaker (1) \\
Arts administrator (22) & Filmmaker (2) & Promoter (3) \\
Arts retailer (2) & Goldsmith/jeweller (2) & Publishing (3) \\
Author (3) & Graphic designer (1) & Retail (2) \\
Building designer (1) & Horticulturist and landscape & Sound artist (1) \\
Building surveyor (1) & consultant (1) & Sound engineer (3) \\
Choreographer (3) & Leatherworker (1) & Tattooist (1) \\
Cinematographer (3) & Manager (2) & Venue manager (1) \\
Clothing, bags, and jewellery & Manufacturing and sales (3) & Video producer (1) \\
\multicolumn{1}{c}{ designer/manufacturer (2) } & Marketing (2) & Visual artist (15) \\
Community arts worker (3) & Media presenter, journalist, & \\
Curator (1) & producer (7) & \\
\hline
\end{tabular}

of creative activities. Interview questions were far broader than can be discussed here-including the rhythms of daily creative life, business linkages, perceptions of Darwin's strengths and weaknesses as a place to be creative, involvement in Aboriginal creative industries, impacts of seasonality and remoteness, and attitudes to government funding policies and facilities. Several questions were geared towards vernacular perspectives on where creativity was located in the city. Indeed, what transpired in this project was that these overtly geographical questions came to anchor the entire interview process. The catalyst for this was the central role played by maps - material, hard-copy, printed maps - as an interview prompt. These maps, and the stories of the location of creativity in the city they enabled, are the focus here.

\section{Mapping creative activities}

Where maps have been used previously to analyse the locations of creativity in the city, they have tended to be choropleth maps. These assign a colour ramp to a map so that each geographical area, such as a suburb or postcode, is shaded a particular colour based on the number of creative activity firms or employees found within its bounds (eg DCMS, 2008; Gibson et al 2002). These sorts of maps are useful for displaying broad trends across a city or region but, as discussed previously, if they are based on census counts, or other such official sources, they are bound to miss a significant proportion of creative individuals, particularly those in the informal sector, the various spheres of vernacular creativity, or those pursuing radical political ends.

What was required for the Darwin project was an alternative methodology that could reveal everyday spatial relationships between creative practitioners and the city (Elwood, 2006). Since the primary mode of data collection on the project was in-depth interviews, there needed to be a way for informants to describe their creative activities graphically on a map. Accordingly, we revisited the older idea in geography of conducting 'mental maps'. 'Mental maps', 'sketch maps', 'cognitive maps', and 'perceptual maps' are interchangeable terms to describe a free-hand mapping technique used to document representations of place (Tuan, 1975). They have been used since the 1960s, principally by behavioural geographers and more recently in participatory geographical information systems (PGIS), to gather multiple viewpoints, to display traditional knowledges (Rambaldi and Callosa-Tarr, 2000), and to empower local communities by capturing spatially people's sense of place (Elwood and Leitner, 1998). In the traditional 
use of mental mapping, an informant draws freehand, resulting in considerable levels of spatial distortion. Researchers make inferences on an individual's orientation, geographic imagination, and bias for particular sites based on the distortion, relative size,

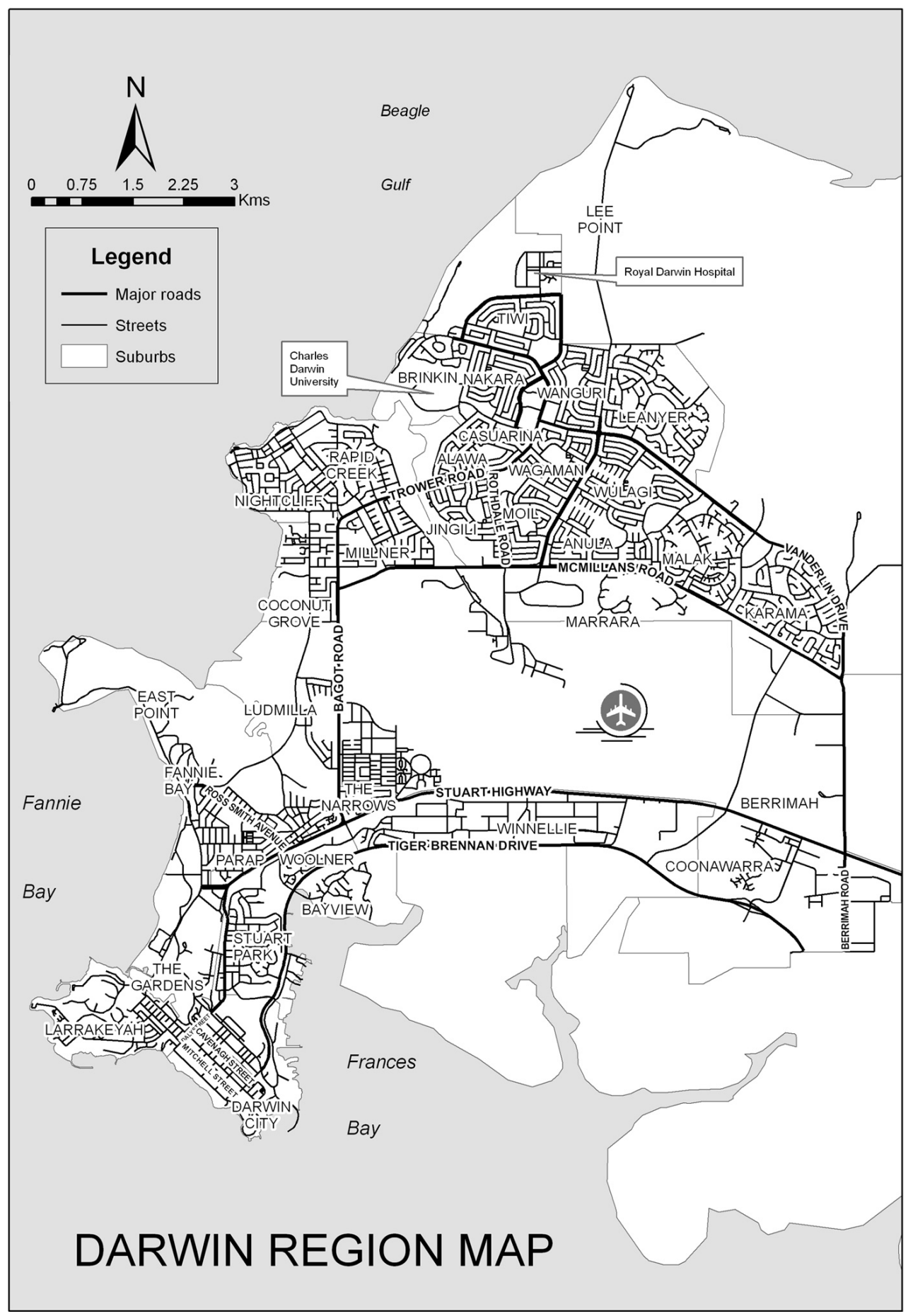

Figure 2. Blank base map used for the mental mapping exercise. 
and strength of relationships of objects that participants draw. A variation was Lynch's (1960) classic work Images of the City, in which he envisaged mental maps of the city as more than an individual's cognitive representation-as a cultural construct (see also Mattei et al, 2001). To this end, mental maps could be utilised

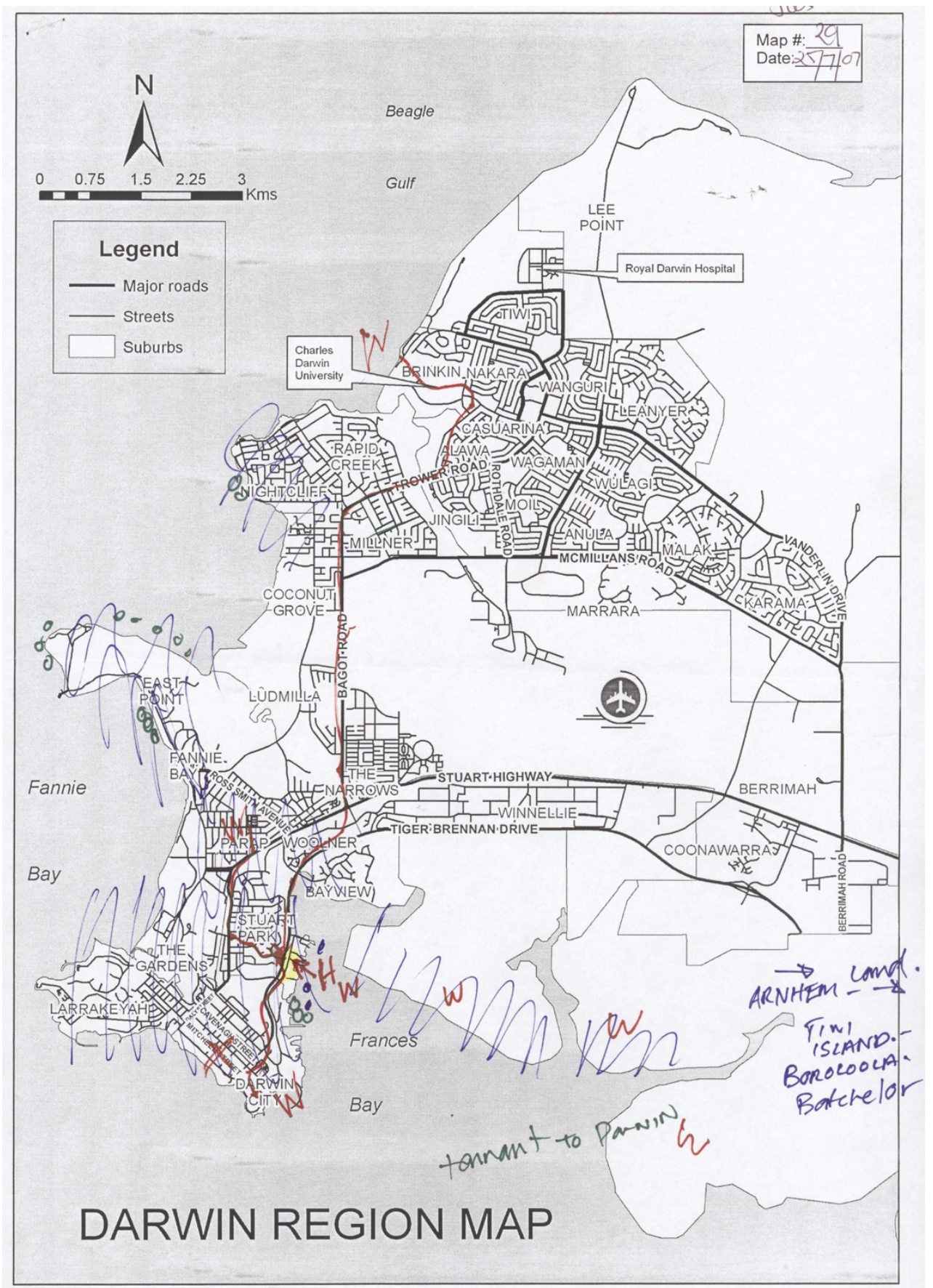

Colour plate 1. Example of completed mental map. 
within interviews to reveal the hidden spatial preferences, cultural meanings, and everyday navigations of the city by creative practitioners.

As has been noted in the PGIS context by Vajjhala (2005, page 6), "most participatory mapping efforts focus on eliciting and recording accurate social information with varying degrees of spatial precision, while GIS maps require a certain degree of spatial precision to correctly illustrate social phenomena". A parallel exists with mental maps, in that they produce graphically rich maps, but in cartographic terms they may be imprecise. This makes collating responses with a GIS problematic, if not impossible. Mental maps drawn on a blank page would need transferring to a simplified graphic form, matching what the informant drew to landmarks with known spatial properties such as a latitude and longitude. This reduced graphic could then be georeferenced to a known coordinate system in the GIS, from which more sophisticated analysis would be possible. However, such processes would invariably result in a loss of data richness (ie meaningful spatial distortion) as each response was reduced and transferred to the GIS. In light of this trade-off between data richness and geographic accuracy, and adapting mental mapping techniques developed by Mattei et al (2001) and Vajjhala (2005), it was decided that a paper base map could be used that had a known projection. ${ }^{(1)}$ Informants would mark their responses on this paper base map and their responses could then be geocoded into a GIS without distortion.

Informants were accordingly provided with a paper base map of Darwin (see figure 2), containing a basic street network and suburb names. A potential weakness was that providing a map with existing placemarks (such as street and suburb names) would lead informants to reply in a certain fashion, or to a particular place. To that end, different base maps were trialled with more or less identifying informationresulting in a final map used for interviewing with 'just enough' information to assist informants in locating themselves in Darwin, but not so much as to lead answers to specific questions. This technique would not be able to document spatial distortions because of the use of a projected base map, meaning that it contrasted somewhat with traditional mental mapping techniques (Peake and Moore, 2004). But, conversely, and as transpired, by introducing a basic, geographically 'accurate' map into interviews, responses to other questions about Darwin such as the city's creative strengths and weaknesses became more spatially specific; geographical literacy was further grounded in participants' thinking and responses. The gains made in accumulating mental map responses in a GIS were considered worthy of the loss of purposeful spatial distortions. During May 2007, prior to fieldwork, the mental mapping technique was piloted with ten creative workers in Sydney. The process and questions were then refined with the project team in Darwin, before interviewing took place between June 2007 and April 2008.

\section{The interview process}

The interview schedule contained a number of early questions of a spatial nature. Informants were asked first to locate their homes and places of work. This aided in orientating informants with the map. Different coloured pens were provided for subsequent spatial questions, including where informants went to gain inspiration, where they felt the epicentre of creative Darwin was, where they went in Darwin

(1) Advances in mobile computing, such as tablet PCs, PDAs, and digital pens, have been advocated by some mental mapping practitioners for understanding spatial cognition (Huynh and Doherty, 2007). Such options were canvassed at the project development stage, but were ruled out due to technical and financial constraints, the time needed to develop dedicated software for our particular needs, and skilling up and managing workflows for the multiple users of the method. Instead, paper continues to be the most common medium for mental mapping and remains an accessible, low-tech device - easy both for an interviewer to administer, and for informants to interact with. 
for recreation, and what routes they took to get between work and home. The aim of each spatial question was to invite reflection on the everyday ways in which creative practitioners use their city and, by inference, reveal any latent spatial relationships between different creative individuals or groups. Participants drew on their base map, and elaborated on their markings by qualitatively describing their creative life and how it interacted with the city.

Other than ask interviewees to use certain coloured pens to answer different questions, participants were allowed to respond on the map in whatever fashion they saw fit. A few respondents, ever creative(!), felt their options were being limited and wanted more coloured pens to draw with, beyond the four that were provided. Most, however, were content to work with what they were given.

An example of a completed mental map is shown in colour plate 1 . There were considerable - and welcome-variations in the manner in which people recorded their spatial perspectives. Some cross-hatched broad areas in response to certain questions (and, for instance, discussed creativity in these areas relation to sociocultural scenes); others drew specific routes of movement as accurately as possible, following precise street networks and describing specific parts of their individual creative lives; others again drew connecting lines to places well beyond the confines of the map-such as to remote Aboriginal communities, and further again into Southeast Asia, where they moved through and traded for work.

Full analysis of the range of results from this process is not possible here: instead, we share the results of just one interview question- "Where is Darwin's creative epicentre?" - to highlight how this mix of interview and GIS methods is capable of revealing diversity and richness for creative city research. The maps and discussion here are only based on this single interview question [see Lea et al (2009) for results of other mapping questions], which returned 83 completed maps. Composite maps shown here were produced from these 83 compiled responses.

For this particular question, respondents were given a yellow highlighter to mark their responses. They were permitted to draw in any way they deemed fit, and were allowed to respond to more than one place if desired. A total of 43 interviewees $(52 \%)$ responded by identifying more than one area/site. Responses to this question were then transferred into the GIS, by scanning each map with an A3 flatbed scanner, converting the paper map into a digital image in jpeg format at 300 dpi. Each map was then georeferenced to the Darwin road network using ArcGIS v9.2. Responses to each of the spatial questions were heads-up digitised using ArcMap editor (ie redrawn on-screen using the scanned images of hard-copy maps), resulting in a traced outline of each response. These were saved in shapefile format, the ArcGIS proprietary file type for storing vector data.

\section{Analysing interview maps in GIS}

How to analyse this data-and what geographical patterns prevailed-depended on the specific GIS techniques adopted.

The first technique involved simple overlaying of each respondent's maps in the digital environment, to see which geographical areas were most commonly identified. To achieve this, each shapefile was converted to raster format, a pixel image format, where each cell is assigned a colour based on its value. Using ArcGIS Spatial Analyst toolset, raster images can be combined together, through the use of map algebra functions. Pixels with the greatest score are sites most often drawn on the paper map by informants.

Colour plate 2 displays the mean pixel score for all 83 responses to the creative epicentre question. Colours range from yellow through to red, ramping up to show 
increasing spatial correspondence of responses. Revealed through this process are three distinct zones in Darwin which informants most commonly identified as creative epicentres: the city centre (CBD), and the northern suburbs of Parap and Nightcliff. The most commonly identified was Parap (in 39\% of responses). Parap is a mediumdensity to low-density residential suburb, at some distance from the city centre, with a small but changing local shopping centre that contains speciality shops servicing the artistic sector (eg art supplies store, framing shop), a couple of cafes and restaurants, grocery stores, and other typical local shops such as newsagents and pharmacies.

The identification of Parap as Darwin's most popular creative epicentre was somewhat unexpected. It garnered more responses than other places in central Darwin which we expected would score more highly - such as Mitchell Street, home to the city's nightlife and backpacker scene; or precincts surrounding Darwin's art galleries, museums, and large entertainment centre auditorium. Notably, none of the interviewed government officials in ministries of the Arts, cultural planning, or museums and galleries mentioned Parap: instead, more predictably, they nominated central city areas around 'flagship' buildings. Findings from creative-city mapping elsewhere-focused on designated cultural precincts, large institutions, gentrifying inner-city areas, and 'funky' neighbourhoods, especially ex-industrial spaces - appear somewhat contradicted in the case of Parap. Instead, Darwin's urban form, radically reshaped by war, cyclones, and reconstructions, has meant that creativity inevitably has a suburban geography. A mapping exercise focusing on the vernacular perspective revealed this more decentred geography.

Two of Parap's major strengths are the presence of the fringe art gallery, 24 Hour Art, which houses exhibitions from local and visiting artists, and the weekly Parap outdoor markets. Darwin's tropical outdoor culture allows it to sustain a number of community markets. One of the longest running and year-round is the weekly Parap
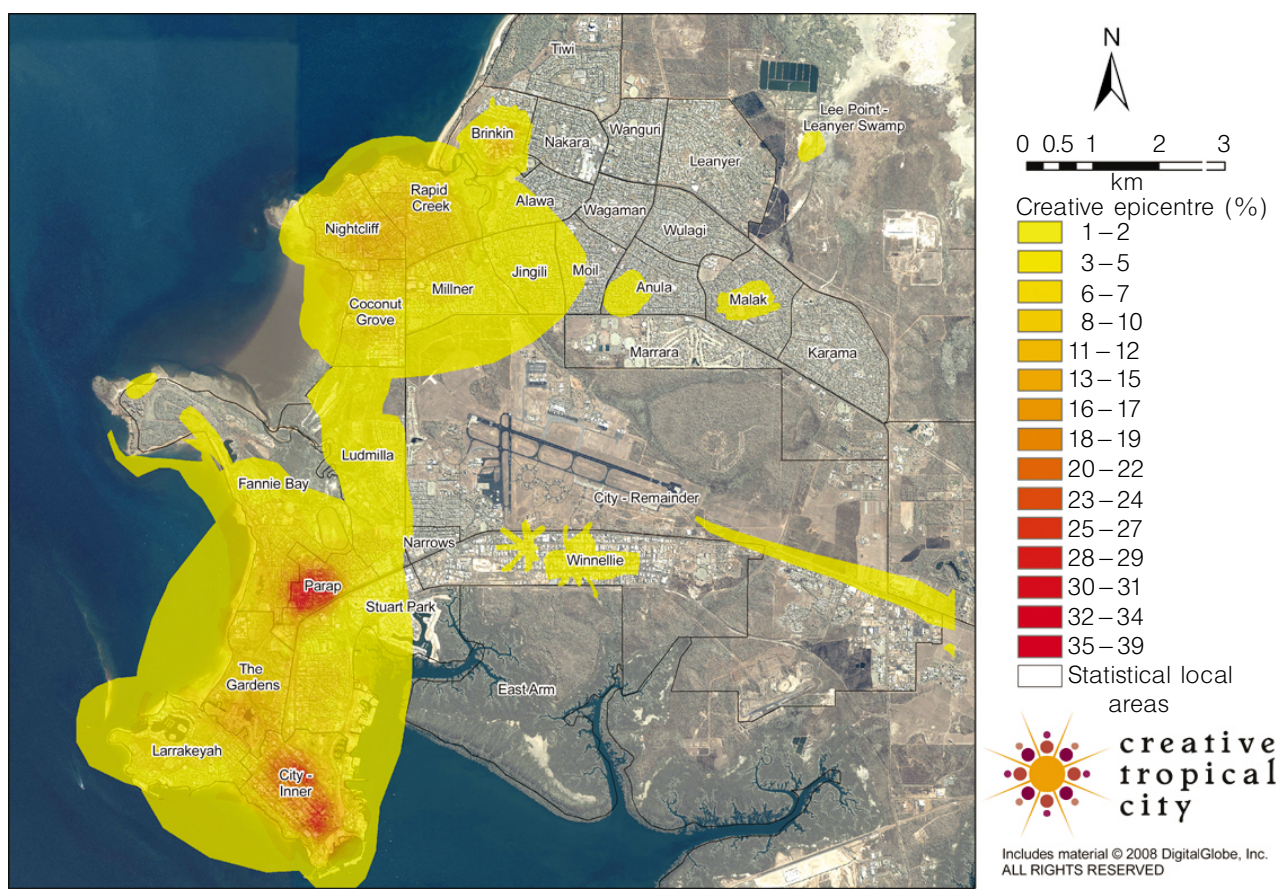

Includes material $\odot 2008$ DigitalGlobe, Inc ALL RIGHTS RESERVED

Colour plate 2. Darwin's creative epicentres, 2008. 
Market which, with a more relaxed and community vibe, is less tourist-focused than the bigger Mindl Beach Night Markets. For one graphic designer:

"I think there's pockets of creativity within Darwin and they seem to be in the older suburbs ... Parap's one of them. They've got a lot of art stores there, with Tiwi art, and Nomad's just moved and opened, but also, not just the indigenous culture, but the markets, the Asian markets and that influence is really huge too, from a village, like a community point of view. It's one reason why I bought my house in Parap, I wanted to live walking distance to the markets."

Parap Market is a lifestyle attraction and a meeting place for visual artists, craft producers, and designers; they also bring visitors, including more intrepid tourists, underpinning the viability of nearby art galleries and cafes. For a film-maker and visual artist:

"I like the markets there, and I like to be able to get something to eat, buy some art materials and have a look at the raft gallery there."

Although Parap emerged as the most frequently identified 'epicentre' using the mean pixel score method, it would be hasty indeed to conclude that it alone was the premier geographical location of creativity. Darwin's city centre was still expected to figure as a creative epicentre, given the concentration of workplaces, of consumption sites including venues and galleries, and, importantly for many creative sectors, access to tourist audiences. For certain sectors of Darwin's creative economy, including music performance and artistic display, access to audience numbers bolstered by tourist influxes is significant given that Darwin has a small population [and thus limited endogenous market for creative products (see Luckman et al 2008)].

Although the mean pixel score method revealed Parap as the premier epicentre, another way of analysing mapped responses in the GIS revealed a story much more focused on the city centre - and, crucially, told by respondents in a qualitatively different manner. This involved tallying how many responses were drawn on maps within or intersecting with the boundaries of each of Darwin's suburbs-known as Statistical Local Areas (SLAs) in the Australian system (figure 3). This technique of aggregating responses to larger spatial units revealed that the city centre is by far the main epicentre. This was due to two factors. First, the SLA of Inner City is larger in size than Parap, and thus potentially more likely to capture responses; and second, because of its wide array of facilities and venues, a more spatially diverse mix of responses was able to be captured. For those identifying Parap as a creative epicentre, the bulk of creative activities were said to have occurred in or near its retail precinct-a small area where the markets are held, consisting of one rectangular carpark surrounded on three sides by a mix of retail shops. Pinpointing this site on a hand-drawn map was easy, and hence more responses 'lined up' on top of each other in the aggregated map, giving Parap a greater average pixel score. By contrast, respondents tended to name particular streets, venues, cafes, or arts facilities in the city centre, such as Mitchell St. The tendency was not to draw a broad boundary around the central city area and identify it as a whole as an 'epicentre', but to identify several city-centre locations specifically. Thus, diversity among interviewees (across the many different backgrounds and pursuits of those interviewed) was reproduced in diverse-and more spatially specific-identifications of sites in the city centre that were important to them as central creative spaces. Some were obvious choices such as galleries and notable music venues; others were unpredictably diverse; such as specific cafes, art supplies stores (including unglamorous local hardware stores), the central offices of design or architecture firms, or collectively owned artist facilities. Such spaces may be proximate, but unless the scribbles and pen-marks of respondents on hard-copy maps overlapped, their inputs would not add together in the mean pixel score method to 


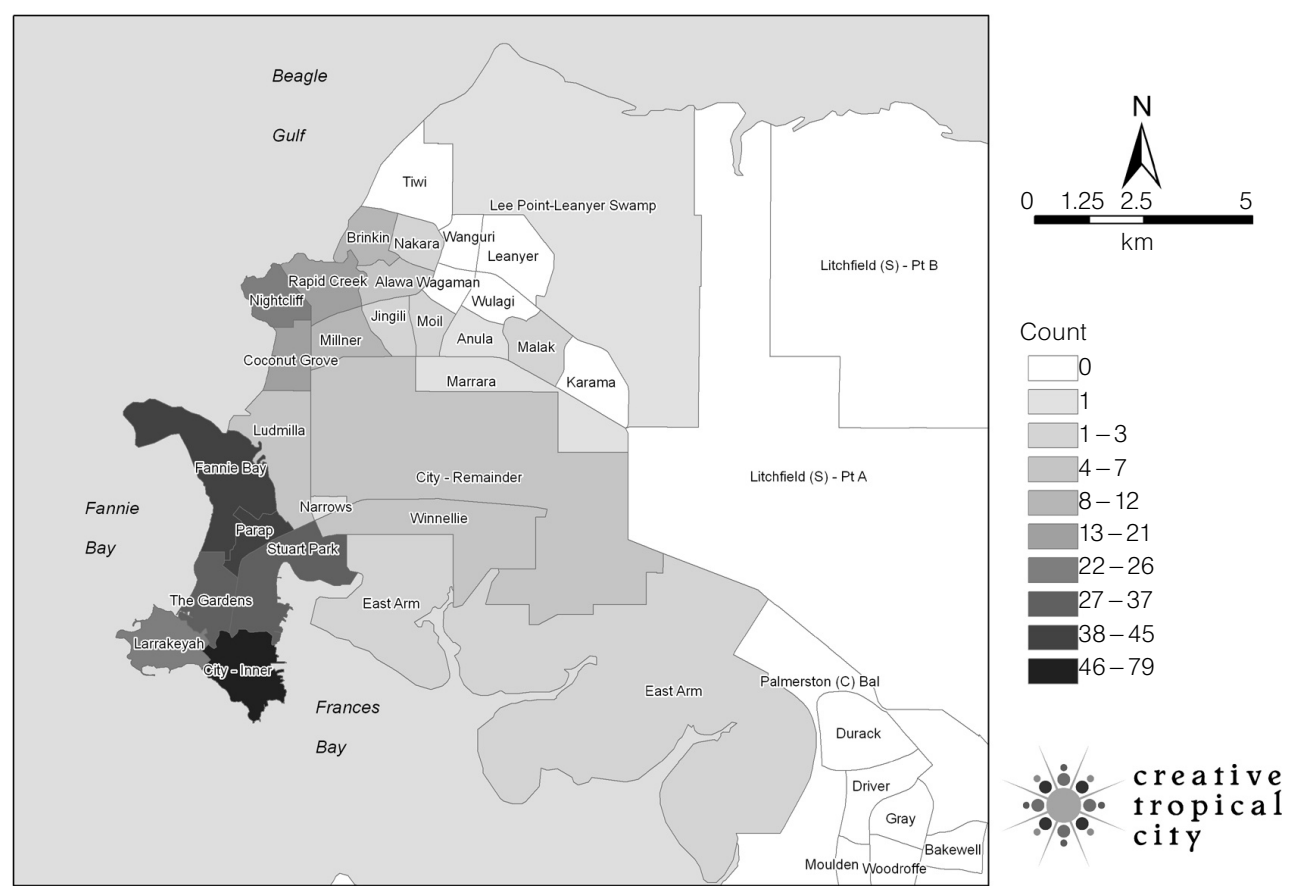

Figure 3. Map of Darwin's creative epicentres, aggregated to statistical local area (SLA) boundaries, 2008.

produce a greater creative epicentre score. They were captured instead by aggregating individual responses to larger spatial boundaries.

Another means of revealing qualitative differences in how people identified creativity geographically was to tabulate maps by type of response. The spatial database constructed from the mental maps could interrogate whether there were relationships between how informants responded on the blank base map-literally, how they chose to draw and explain their geographical identifications - and where they chose to mark these responses. We grouped responses into three categories: markings intended to encompass large areas, usually covering more than one SLA; small markings, which correspond to a space smaller than an SLA, but still indicate a general area or precinct; and refined markings - responses indicating a particular street, venue, building, or block. Table 2 shows a cross tabulation of answers to the 'epicentre' question by type of response. To simplify further, epicentre data in table 2 are also grouped spatially into four zones: Parap; the city centre; Nightcliff, and 'other SLAs' - meaning

Table 2. Responses to the question "Where is Darwin's creative epicentre?", by type and geographical zone.

\begin{tabular}{lcllll}
\hline $\begin{array}{l}\text { Epicentre marking } \\
\text { type }\end{array}$ & \multicolumn{6}{l}{ Geographical zone } & & \\
\cline { 2 - 6 } & $\begin{array}{l}\text { city centre } \\
(\%)\end{array}$ & $\begin{array}{l}\text { Parap } \\
(\%)\end{array}$ & $\begin{array}{l}\text { Nightcliff } \\
(\%)\end{array}$ & $\begin{array}{l}\text { other SLAs a } \\
(\%)\end{array}$ & $\begin{array}{l}\text { total } \\
(\%)\end{array}$ \\
\hline Large & 21 & 33 & 46 & 17 & 26 \\
Refined & 52 & 30 & 23 & 52 & 43 \\
Small & 27 & 37 & 31 & 31 & 31 \\
Total & 100 & 100 & 100 & 100 & 100
\end{tabular}

${ }^{a}$ SLA-Statisical local area. 
Table 3. Responses to the question "Where is Darwin's creative epicentre?", by groups of creative practitioners and geographical zone.

\begin{tabular}{|c|c|c|c|c|c|c|c|c|c|c|c|c|c|c|}
\hline \multirow[t]{2}{*}{ Creative group } & \multicolumn{3}{|c|}{ City centre } & \multicolumn{3}{|l|}{ Parap } & \multicolumn{3}{|c|}{ Nightcliff } & \multicolumn{3}{|c|}{ Other SLAs ${ }^{a}$} & \multicolumn{2}{|c|}{ Total Darwin } \\
\hline & number & $\begin{array}{l}\% \text { of } \\
\text { city- } \\
\text { centre } \\
\text { responses }\end{array}$ & $\begin{array}{l}\% \text { of } \\
\text { group's } \\
\text { responses }\end{array}$ & number & $\begin{array}{l}\% \text { of } \\
\text { Parap } \\
\text { responses }\end{array}$ & $\begin{array}{l}\% \text { of } \\
\text { group's } \\
\text { responses }\end{array}$ & number & $\begin{array}{l}\% \text { of } \\
\text { Nightcliff } \\
\text { responses }\end{array}$ & $\begin{array}{l}\% \text { of } \\
\text { group's } \\
\text { responses }\end{array}$ & number & $\begin{array}{l}\% \text { of } \\
\text { other } \\
\text { SLA } \\
\text { responses }\end{array}$ & $\begin{array}{l}\% \text { of } \\
\text { group's } \\
\text { responses }\end{array}$ & total & $\begin{array}{l}\% \text { of } \\
\text { total }\end{array}$ \\
\hline $\begin{array}{l}\text { Architecture, } \\
\text { design, and } \\
\text { visual arts }\end{array}$ & 28 & 36 & 43 & 17 & 40 & 26 & 8 & 31 & 12 & 12 & 23 & 18 & 65 & 33 \\
\hline Other & 15 & 19 & 28 & 13 & 30 & 25 & 5 & 19 & 9 & 20 & 38 & 38 & 53 & 27 \\
\hline $\begin{array}{l}\text { Music and } \\
\text { performing } \\
\text { arts }\end{array}$ & 19 & 25 & 42 & 3 & 7 & 7 & 9 & 35 & 20 & 14 & 27 & 31 & 45 & 23 \\
\hline $\begin{array}{l}\text { Film, } \mathrm{TV} \text {, and } \\
\text { radio }\end{array}$ & 8 & 10 & 40 & 6 & 14 & 30 & 4 & 15 & 20 & 2 & 4 & 10 & 20 & 10 \\
\hline Publishing & 5 & 6 & 50 & 2 & 5 & 20 & 0 & 0 & 0 & 3 & 6 & 30 & 10 & 5 \\
\hline $\begin{array}{l}\text { Advertising and } \\
\text { marketing }\end{array}$ & 2 & 3 & 50 & 1 & 2 & 25 & 0 & 0 & 0 & 1 & 2 & 25 & 4 & 2 \\
\hline $\begin{array}{l}\text { Software and } \\
\text { interactive } \\
\text { content }\end{array}$ & 0 & 0 & 0 & 1 & 2 & 100 & 0 & 0 & 0 & 0 & 0 & 0 & 1 & 0 \\
\hline Total & 77 & 100 & & 43 & 100 & & 26 & 100 & & 52 & 100 & & 198 & 100 \\
\hline
\end{tabular}


the remainder of the metropolitan area of Darwin. For the whole of the city, most responses $(74 \%)$ were refined or small markings rather than large markings. If given a map with enough detail, creative practitioners would respond in a refined fashion and pinpoint specific places rather than just circle broad areas. This trend was even more pronounced for the central city - with over half of all responses of the refined type. Contrasting this, for Nightcliff $46 \%$ of responses were large markings. This suggests that Nightcliff has a more general 'creative vibe' rather than specific creative facilities or attractions (it was also where lots of creative participants happened to live). Of particular note was that the number of refined responses in 'other' outlying areas $(52 \%)$ was on a par with the level recorded for the city centre, suggesting that even outside commonly chosen precincts or central tourist and business districts, there are many more scattered, but cumulatively no less important, specific places of home and/or work in creativity.

The technique could also interrogate whether there were links between types of creative practitioners and their geographical identification of creative epicentres. This was achieved by intersecting each epicentre response with the SLA boundary layer, and counting how many responses occurred in each SLA from particular groups of creative practitioners (table 3). Groupings used were based on a previous comparable study categorising creative work (Higgs and Cunningham, 2007). For most creative practitioners, there was indeed a preference toward the city centre as Darwin's creative epicentre, a finding corresponding with the map in colour plate 2. But divergent results were found within this broad trend. City-centre identification over other locations was most prevalent for workers in the publishing, advertising, and marketing groups, while in the very diverse 'other' category, respondents were more likely to locate the creative epicentre outside those locations numerically dominant (ie they were most likely to locate creative elsewhere than the CBD, Parap, or Nightcliff). In some groups, both the city centre and suburban Parap were popular (eg film, TV, and radio). More respondents in the architecture, design, and visual arts group identified the city centre than Parap or elsewhere, yet more Parap responses were from this group than any other group of creative practitioners. For musicians and performing artists, the city centre was particularly popular (reflecting the tourist orientation of venues), and Nightcliff was located three times more often than Parap. For this group of creative practitioners, the location most commonly seen as epicentre using the mean pixel score method (Parap) was effectively irrelevant. Even from just one simple interview question, then, a range of divergent and even contradictory stories can be documented about where creativity resides and is enacted in the different spaces of the city.

\section{Conclusion}

Our aim in this paper has been to propose a new method to understand the location of creativity in the city. Spurred by the realisation that empirical research techniques were limited in this unusual setting, we looked instead to a combination of ethnography and GIS maps to understand better where Darwin's creative economy interacts with the city. While ethnographic interviewing in creative city/creative industries research is not new (eg Bain, 2004; Drake, 2003; Gibson, 2003), in this project we explored the use of maps as anchoring devices for interviews, and as a new way of capturing geographical data on creativity in the city. Feedback from the interview-mapping method was positive: informants enjoyed the process, liked being able to use maps as anchors to their discussions, and were keen to see results. To this end, a public exhibition took place at the conclusion of our project at which maps and qualitative stories of creativity in Darwin were combined. Issues not explored here concern the feedback from 
this exhibition, sharing of data among creative workers, and the levels of participation interviewees have negotiated in the research process (cf Elwood, 2008).

Beyond these issues, we make three conclusions relevant to the wider field of creative city research.

First, despite some limitations (such as loss of useful mental mapping distortion), the qualitative spatial data collection and analysis undertaken here proved applicable to creative city research and can address many of the limitations of 'official' data sources, including census data underrepresentation, coarseness of resolution, and exclusion of 'marginal' and informal economic activities. Furthermore, combinations of interviews and mapping methods answer calls in the literature for more ethnographic and spatial accounts of vernacular creativity, to build on quantitative analysis or to transcend its conceptual and empirical limitations (see Gibson, 2003, Pratt, 2004; Shorthose, 2004).

Second, and in answer to the question of where creativity is in the city, new methods combining qualitative ethnographic insights and new digital technologies ought to be further pursued to reveal the more nuanced and differentiated geographies of economic activity in the city. This particularly applies to how workers (in any given industry) experience their working lives. For some participants in our study, a creative epicentre only existed where they worked (as in Winnellie, a warehousing and lightindustry precinct). For others, areas that resonated most strongly either contained or were operating as locations for creative networking, providing a space for interaction, sharing of tacit knowledge, and furthering of creative networks (cf Neff, 2005; Neff et al, 2005). For others, creativity existed where an artist would go to exhibit and sell work (such as suburban Parap or at a gallery in the city centre geared towards tourists); or simply where they lived - especially in the case of home-based work. These creative modes (ie work, home, network) spatially manifest and combine in various configurations, as evidenced in Parap, a place with facilities where people can exhibit, perform or undertake work, network with others, or reside. It must be stressed that these examples are by no means mutually exclusive. Sites of work - networking - home can be separate, or at times intersect in these zones. Beyond the visible centres of creativity, as much activity again was recorded in scattered, atomised locations. Analysis could further explore intersections between the different aspects of creative lives, developing insights into the creative nexus between work, home, inspiration, and recreation.

Finally, what the results of this research technique suggest is that there are dangers in developing creative industry policies without requisite critical reflection on the empirical methods used to examine the spatial and economic character of creative industries (Christophers, 2008; Rantisi et al, 2006; Scott, 2006b). The fostering and, in some cases, wholesale invention of creative 'clusters' and 'precincts' has been popular in policy circles and is the most dominant discourse for the governance of creative industries (for critiques see Gibson and Kong, 2005; Martin and Sunley, 2003). But policy making needs to keep in mind the specificities and limitations of empirical research, and the broader spatial and social contexts of creative sectors and individuals. Pratt (2004, page 62) has, for instance, argued that even though it is

"widely accepted that a 'creative cluster' (the co-location of creative industries) may represent one aspect of the production system's footprint in one locality ... the concept fails to capture the broader spatial, temporal and organisational dynamics of production across the creative industries."

Our research method helps to reveal the personal, social, and geographically divergent ways in which creativity is located within and beyond the city. The geography of creativity is simultaneously imagined as concentrated and dispersed, networked and 
site-specific; contingent on the perspective of the beholder. Creative work relies on multiple and singular, and inspirational and mundane sites of activity.

Acknowledgements. We offer thanks to the anonymous reviewers who gave sympathetic and constructive suggestions for revising this paper, and to the other members of the Darwin research team, especially Susan Luckman and Julie Willoughby-Smith for their stewardship of the project's ethnographic phase.

\section{References}

Bain A L, 2004, "In/visible geographies: absence, emergence, presence, and the fine art of identity construction" Tijdschrift voor Economische en Sociale Geografie $95419-426$

Banks M, 2006, "Moral economy and cultural work" Sociology $40455-472$

Bathelt H, Gräf A, 2008, "Internal and external dynamics of the Munich film and TV industry cluster, and limitations to future growth" Environment and Planning A 40 1944-1965

Bathelt H, Malmberg A, Maskell P, 2005, "Clusters and knowledge: local buzz, global pipelines and the process of knowledge creation" Progress in Human Geography $2831-56$

Brennan-Horley C, 2007, "Work and play: vagaries surrounding contemporary cultural production in Sydney's dance music culture" Media International Australia 123123 - 137

Christophers B, 2008, "The BBC, the creative class, and neoliberal urbanism in the north of England" Environment and Planning A $402313-2329$

Cohen S, 2007 Decline, Renewal and the City in Popular Music Culture: Beyond the Beatles (Ashgate, Aldershot, Hants)

Costa P, Magalhães M, Vasconcelos B, Sugahara G, 2007, "A discussion on the governance of 'creative cities': some insights for policy action" Norsk Geografisk Tidsskrift 61122 - 132

Dahlström M, Hermelin B, 2007, "Creative industries, spatiality and flexibility: the example of film production" Norsk Geografisk Tidsskrift 61111 - 121

DCMS, 2008 Creative Britain: New Talents for the New Economy Department for Culture, Media and Sport, London

Drake G, 2003, “'This place gives me space': place and creativity in the creative industries” Geoforum $34511-524$

Elwood S, 2006, "Negotiating knowledge production: the everyday inclusions, exclusions, and contradictions of participatory GIS research" The Professional Geographer 58 197-208

Elwood S, 2008, "Grassroots groups as stakeholders in spatial data infrastructures: challenges and opportunities for local data development and sharing" International Journal of Geographic Information Science $2271-90$

Elwood S, Leitner, H 1998, "GIS and community based planning: exploring the diversity of neighbourhood perspectives and needs" Cartography and Geographic Information Science $2577-88$

Evans G, Foord J, 2008, "Cultural mapping and sustainable communities: planning for the arts revisited" Cultural Trends 17 65-96

Fasche M, 2006, "Creative people and gentrification: 'sowing the seeds of demise?' Evidence from Newtown, Sydney" Erdkunde 60147 - 156

Flew T, Ching G, Stafford A, Tacchi J, 2001 Music Industry Development and Brisbane's Future as a Creative City Queensland University of Technology and Brisbane City Council, Brisbane

Florida R, 2002 The Rise of the Creative Class (Basic Books, New York)

Gibson C, 2000 Decentred Sounds: Systems of Provision for Popular Music and a Regional Music Industry $\mathrm{PhD}$ thesis, Department of Geography, University of Sydney

Gibson C, 2003, "Cultures at work: why 'culture' matters in research on the 'cultural' industries" Social and Cultural Geography $4201-215$

Gibson C, Brennan-Horley, C 2006, "Goodbye pram city: beyond inner/outer zone binaries in creative city research" Urban Policy and Research 24 455-471

Gibson C, Brennan-Horley C, 2007 Creative Tropical City: Statistical Data Analysis Report for Darwin City Council, NRETA, and Tourism NT, University of Wollongong, Wollongong

Gibson C, Klocker N, 2005, "The 'cultural turn' in Australian regional economic development discourse: neoliberalising creativity?" Geographical Research 4393 - 102

Gibson C, Kong L, 2005, "Cultural economy: a critical review" Progress in Human Geography $29541-561$

Gibson C, Murphy P, Freestone R, 2002, "Employment and socio-spatial relations in Australia's cultural economy" Australian Geographer 33 173-189 
Gill R, Pratt A, 2008, "In the social factory? Immaterial labour, precariousness and cultural work" Theory, Culture and Society $251-30$

Grabher G (Ed.), 2002, "Production in projects: economic geographies of temporary collaboration" Regional Studies $36205-322$

Hayward P, 2005, "Locally mixed: a report on Darwin's musical heritage and opportunities to sustain and develop it as a focal cultural identity for the city", Department of the Chief Minister, Northern Territory Government, Darwin

Hearn G, Ninan A, Rogers I, Cunningham S, Luckman S, 2004, "From the margins to the mainstream: creating value in Queensland's music industry" Media International Australia $112101-114$

Higgs P L, Cunningham S D, 2007 Australia's Creative Economy: Mapping Methodologies CCI, Queensland University of Technology, Brisbane

Huynh N, Doherty S, 2007, "Digital sketch-map drawing as an instrument to collect data on spatial cognition" Cartographica $42285-296$

Kong L, Gibson C, Khoo, L-M, Semple, A-L, 2006, "Knowledges of the creative economy: towards a relational geography of diffusion and adaptation in Asia" Asia Pacific Viewpoint $47173-194$

Lea T, Luckman S, Gibson C, Fitzpatrick D, Brennan-Horley C, Willoughby-Smith J, Hughes K, 2009 Creative Tropical City: Mapping Darwin's Creative Industries (Charles Darwin University Press, Darwin)

Luckman S, Gibson C, Willoughby-Smith J, Brennan-Horley C, 2008, "Life in a northern (Australian) town: Darwin's mercurial music scene" Continuum: Journal of Media and Cultural Studies $22621-634$

Luckman S, Gibson C, Lea T, 2009, "Mosquitoes in the mix: how transferable is creative city thinking?" Singapore Journal of Tropical Geography 30 47-63

Lynch K, 1960 The Image of the City (MIT Press, Cambridge, MA)

McRobbie A, 2002, "From Holloway to Hollywood: happiness at work in the new cultural economy?", in Cultural Economy Eds P du Gay, M Pryke (Sage, London) pp 97 - 114

Markusen A, Wassall G H, DeNatale D, Cohen R, 2008, "Defining the creative economy: industry and occupational approaches" Economic Development Quarterly 22 24-45

Martin R, Sunley, P 2003, "Deconstructing clusters: chaotic concept of policy panacea" Journal of Economic Geography 3 5-35

Maskell P, Malmberg, A, 1999, "Localised learning and industrial competitiveness" Cambridge Journal of Economics 23167 - 185

Mattei S, Ball-Rokeach S, Qiu J, 2001, "Fear and misperception of Los Angeles urban space: a spatial-statistical study of communication-shaped mental maps" Communication Research $28429-463$

Neff G, 2005, "The changing place of cultural production: the location of social networks in a digital media industry" Annals of the American Academy of Political and Social Sciences 597 $134-152$

Neff G, Wissinger E, Zukin S, 2005, "Entrepreneurial labor among cultural producers: 'cool' jobs in 'hot' industries" Social Semiotics 15307 - 334

Oakley K, 2004, "Not so cool Britannia: the role of the creative industries in economic development" International Journal of Cultural Studies $767-77$

Oakley, K 2006, "Include us out-economic development and social policy in the creative industries" Cultural Trends $15255-273$

Pappalepore, I 2008, “Tourism development in non-central London creative quarters", paper presented at the Royal Geographical Society and Institute of British Geographers annual conference, London, 27-29 August; copy available from the author, The Centre for Tourism Research, University of Westminster, London

Peake S, Moore T, 2004, "Analysis of distortions in a mental map using GPS and GIS", Paper presented at SIRC 2004 - 16th Annual Colloquium of the Spatial Information Research Centre, University of Otago, Dunedin, 29-30 November, http://eprints.otago.ac.nz/142/01/19_Peake.pdf

Peck J, 2005, "Struggling with the creative class" International Journal of Urban and Regional Research $29740-770$

Power D, Scott A (Eds), 2004 The Cultural Industries and The Production of Culture (Routledge, London)

Pratt A C, 1997, "The cultural industries production system: a case study of employment change in Britain, 1984-91" Environment and Planning A 291953 - 1974 
Pratt A C, 2004, "Creative clusters: towards the governance of the creative industries production system" Media International Australia 112 50-66

Rambaldi G, Callosa-Tarr J, 2000 Manual on Participatory 3-D Modeling for Natural Resource Management National Integrated Protected Areas Programme, Quezon City, Philippines

Rantisi N, Leslie D, Christopherson S, 2006, "Placing the creative economy: scale, politics, and the material" Environment and Planning A 381789 - 1797

Reimer S, 2009, "Geographies of production II: fashion, creativity and fragmented labour" Progress in Human Geography 33 65-73

Reimer S, Pinch S, Sunley P, 2008, "Design spaces: agglomeration and creativity in British design spaces" Geografiska Annaler, Series B: Human Geography 90151 - 172

Ross N, 2008, "The new geography of work: power to the precarious?" Theory, Culture and Society $2531-49$

Rossiter N, de Muynck B, Carriço M (Eds), 2008, "Counter-mapping the creative industries" Urban China $33 \mathrm{http}: / /$ orgnets.net/publications

Scott A J, 2000 The Cultural Economy of Cities (Sage, London)

Scott A J, 2006a, "Entrepreneurship, innovation and industrial development: geography and the creative field revisited" Small Business Economics 26 1-24

Scott A J, 2006b, "Creative cities: conceptual issues and policy questions" Journal of Urban Affairs $281-17$

Shorthose J, 2004, "Accounting for independent creativity in the new cultural economy" Media International Australia 112150 - 161

Throsby D, 2001, "Defining the artistic workforce: the Australian experience" Poetics 28255 - 271

Throsby D, 2008, "The concentric circles model of the cultural industries" Cultural Trends 17 $147-164$

Tuan, Y-F, 1975, "Images and mental maps" Annals of the Association of American Geographers $65205-213$

Vajjhala S, 2005, "Integrating GIS and participatory mapping in community development planning", in Proceedings of the Twenty-Fifth annual ESRI User Conference, San Diego, CA http://gis.esri.com/library/userconf/proc05/papers/pap1622.pdf

Vang J, 2007, "The spatial organization of the news industry: questioning assumptions about knowledge externalities for clustering creative industries" Innovation: Management, Policy and Practice $914-27$

Walker M A, 2008, "The cultural economy of a border renaissance: politics and practices in the city" Space and Polity $11185-200$

Ward K, 2003, "Entrepreneurial urbanism, state restructuring and civilizing 'new' East Manchester" Area 35116 - 127

Watson A, 2008, "Global music city: knowledge and geographical proximity in London's recorded music industry" Area $\mathbf{4 0} 12-23$

Wilson D, Keil R, 2008, "The real creative class" Social and Cultural Geography 9841 - 847

Wittel A, 2001, "Towards a network sociality" Theory, Culture and Society 1851 - 57 
Conditions of use. This article may be downloaded from the E\&P website for personal research by members of subscribing organisations. This PDF may not be placed on any website (or other online distribution system) without permission of the publisher. 